\title{
Through the looking glass: CNS imaging findings in HAM/TSP
}

Raya Massoud

From 16th International Conference on Human Retroviruses: HTLV and Related Viruses

Montreal, Canada. 26-30 June 2013

No abstract submitted

Published: 7 January 2014

\author{
doi:10.1186/1742-4690-11-S1-029 \\ Cite this article as: Massoud: Through the looking glass: CNS imaging \\ findings in HAM/TSP. Retrovirology 2014 11(Suppl 1):O29.
}

- Convenient online submission

- Thorough peer review

- No space constraints or color figure charges

- Immediate publication on acceptance

- Inclusion in PubMed, CAS, Scopus and Google Scholar

- Research which is freely available for redistribution 